\title{
Situated mapping: visualizing urban inequality between the god trick and strategic positivism
}

Forthcoming in ACME: An International Journal for Critical Geographies

Taylor Shelton

Department of Geosciences

Georgia State University

jshelton19@gsu.edu

\begin{abstract}
This paper asks, and seeks to answer, the question: what makes mapping critical? I argue that most examples of 'doing' critical mapping tend to fall into one of two camps with very different manifestations, goals and assumptions, whether from Donna Haraway's invocation of - and desire to counteract - what she calls the "god trick", or from the spirit of "strategic positivism" advocated by the geographer Elvin Wyly. The rest of the paper argues, however, that these two positions are not mutually exclusive, and that practitioners of critical mapping need not choose between the twin imperatives of destabilizing our understanding of the objectivity of cartographic knowledge and taking advantage of such a pervasive understanding in order to produce a more socially and spatially just world. Instead, I argue that it is possible to simultaneously use maps to prove that inequality exists, while also demonstrating that the ways we conventionally think about such inequalities through maps are insufficient to understand the complex realities of the processes that we are mapping. Using examples from my own research on mapping the relational geographies of vacant and abandoned properties in Louisville, Kentucky, I demonstrate one possible example of what such an approach to situated mapping might look like.
\end{abstract}




\section{Introduction}

This paper is oriented around the question: what makes mapping critical? Or rather, how do we do critique through the practice of mapping?

While there has been a recent proliferation of interest in critical mapping(s) from both within and beyond the academy, there remains no single way of approaching critical mapping as a practice, nor any real way to identify what makes one map critical and another, well... not. While this paper does not attempt to produce a single, overarching and universalized theorization of critical mapping, it does attempt to provide insight into one of the central, underlying and often unstated tensions within the field. That is, this paper attempts to elucidate the tension between an approach to critical mapping that is focused on challenging the ostensibly objective, positivist epistemology of conventional mapping through creative reworkings of the map, and an approach that is focused on leveraging that seeming objectivity in order to make alternative claims on the world, often in such a way as to prove the existence or importance of social and spatial inequality.

The argument of the paper is twofold. First, that most examples of 'doing' critical mapping tend to fall into one of two camps with very different manifestations, each of which carry a different set of goals and assumptions. As I argue, these two groups can be categorized based on their adherence to the approaches described in either Donna Haraway's (1988) invocation of (and desire to overturn or counteract) what she calls "the god trick" - or the ability to see everything from nowhere in the spirit of objectivity that we very commonly associate with the use of mapping and quantitative data - or in Elvin Wyly's (2009) more recent notion of "strategic positivism", which emphasizes the need to leverage the power of this purported objectivity in order to advance the cause of social and spatial justice.

While I use Haraway and Wyly here to represent two theoretical poles within the world of critical mapping, it is important to note that these theorists do not exist at the extremes of the binary between positivist science and poststructural critique. Indeed, part of their overlap and utility for thinking about critical mapping lies in their shared desire to counteract such a persistent binary. But even as Haraway and Wyly have a substantive overlap in their approaches, within the actual practice of critical mapping there remains a tension between the twin imperatives of destabilizing our understanding of the objectivity of cartographic knowledge and taking advantage of such a pervasive understanding in order to produce more just social and spatial outcomes. Put differently, there is a tension between using maps to prove that space (and the social processes that both 
coalesce within, and indeed go into producing, space) matters, and demonstrating that the ways we conventionally think about space are insufficient in order to actually understand the complex realities of the processes that we are mapping.

The second argument I make in this paper is that better understanding these different visions of critical mapping and their underlying theoretical justifications allows us to put these approaches into conversation with one another and, ultimately, develop a more unified praxis of critical mapping. There is, however, no 'right side' in this argument, nor should there be a singular winner in such an argument. The goal of this paper is instead to hold these two sides in tension and demonstrate the utility of addressing both simultaneously (and the utility of drawing more direct inspiration from Haraway's and Wyly's writings in doing so).

At the same time, however, it is worth mentioning that the use of such prominent white theorists here should not be seen as the be-all and end-all of interrogating the contradictions in critical mapping theory and practice. Drawing on these theorists is not meant to reassert white privilege within the field of critical mapping, but to highlight the persistent tensions within the field that can give rise to a more synthetic approach. Indeed, through this comparison and synthesis, we can attempt to rectify some of the longstanding injustices within the mapping field more broadly, opening up space for the variety of mapping theories and practices being developed by countless marginalized peoples.

In order to explore these issues in more detail, I first turn to elucidating the key insights and arguments of each perspective, and how different approaches to critical mapping have tended to adopt one or the other as their guiding principle. The paper then turns to arguing for a more synthetic approach that I call "situated mapping", and using the example of mapping vacant and abandoned properties in Louisville, Kentucky, as a means of demonstrating the potential of such an approach.

\section{Doing Critical Mapping between the God Trick and Strategic Positivism}

At the same time as interest in critical mapping - and in taking advantage of the exponential growth of new sources of unconventional social data - has grown, so too have emerged significant challenges to the utility of such approaches. It is widely remarked upon that we have now entered into a "post-truth" age, where blind faith, a conviction that one is right and an ability to yell just a little bit louder than your opponents is paramount. This condition has become so evident that on 
the heels of Brexit and the election of Donald Trump, post-truth was named the Oxford Dictionaries' 2016 Word of the Year.

But seeing the last few years as a radical break from that which came before it also poses some significant dangers for us in conceptualizing the role of data and mapping - and of science and truth, more broadly - in our world. As Sheila Jasanoff and Hilton Simmet (2017) argue, that "post-" prefix in post-truth is decidedly ahistorical, in that it assumes we were ever in an era to begin with where objective truths reigned supreme and data was all we needed to prove a point.

Indeed, this is a point made by David Harvey some 45 years ago when he lambasted geographers of the day for their "counter-revolutionary" tendency to "map even more evidence of man's patent inhumanity to man", because "it allows the bleeding-heart liberal in us to pretend we are contributing to a solution when in fact we are not" (Harvey 1973: 144). As he says, "there is already enough information in congressional reports, newspapers, books, articles and so on to provide us with all the evidence we need" (Harvey 1973: 144-145). For Harvey, this retreat into a kind of positivist empiricism was just a form of "moral masturbation" that ultimately "serves to expiate [our] guilt without our ever being forced to face the fundamental issues, let alone do anything about them" (Harvey 1973: 145). All of that is to say that a focus on data has long served as a means of not just uncovering truths about the world but also avoiding them.

It is on this backdrop that we consider the varieties of critical mapping currently being practiced and how these works sit in relation to broader intellectual and political traditions. In doing so, we can begin to understand how these different forms of critical mapping are positioned with respect to this broader challenge of post-truth politics today.

\section{Practicing Strategic Positivism}

For Wyly, strategic positivism represents a way of avoiding the "universalizing [and] decontextualized epistemological truth claims...advocated by hardcore positivists in the midtwentieth century", as well as the "oppositional universality of antifoundational thought" (2009: 316). As Wyly argues further, these more ostensibly scientific methodologies have a distinct role to play in advocating for social change, countering what he calls "the ideological 'facts' performed by a powerful right-wing governmentality machine" (2009: 318). Contra the enormous body of postmodern or poststructural social theory that speaks to questions of injustice and inequality, Wyly argues that most activists have no problem fusing their politics with the tools of positivist 
spatial analysis. Maps and numbers wield social power precisely because of the prevalence of the god trick, so why not use this power towards more socially just ends?

As Wyly suggests, this ethos is on display in a number of examples like the work of the Cedar Grove Institute for Sustainable Communities in North Carolina, which has used GIS extensively in a series of successful lawsuits challenging institutionalized racial inequalities (Joyner and Parnell 2013), such as in the failure of the city of Zanesville, Ohio, to extend water and sewer services to black residents. It is similarly evident in the proliferation of web-based mapping tools, like PolicyMap, the EPA's EJScreen or HUD's now-deprecated Fair Housing Assessment Tool, that are meant to make basic spatial data analysis capabilities more easily accessible to non-experts, who are able to use these "standard tools of classical spatial science to craft rigorous but strategic research that appeals to positivist truth claims to demand accountability and action from the state" (Wyly 2009: 318). In short, these kinds of projects 'do critique' by using spatial data to prove that inequality does indeed exist and make the case that we need to do something about it.

But it is precisely this brand of critical mapping that is most directly challenged by the current post-truth moment. It is increasingly evident that trying to present 'the facts' is not going to convince the neoliberal ideologues in city halls across the country any more than it is going to convince the fascists in the White House, or the various Far-Right movements that support them. Indeed, as Gunnar Olsson writes, "the strength of cartographical reason lies less in its ability to tell the truth and more in its power to convince" (2010: 10). And part of that power to convince lies in shifting the frame through which we understand the world.

\section{Subverting the God Trick}

It is this issue of reconsidering the ontological and epistemological foundations of mapping that Haraway and the cartographic work that exemplifies her scholarship strive to address, albeit to the simultaneous exclusion of some of the concerns raised by work in the spirit of strategic positivism. Rather than presenting that objective, 30,000-foot view, this approach seeks to challenge some of that detachedness by, as Haraway writes, "arguing for politics and epistemologies of location, positionality and situating, where partiality and not universality is the condition of being heard to make rational knowledge claims", advancing a "view from the body...versus the view from above, from nowhere" (Haraway 1988: 589). 
For Haraway, emphasizing the situatedness and particularity of knowledge - the possibility for other ways of knowing - does not make such knowledge any less useful or rational. Instead, by being situated in precisely these more subjective contexts we can instead produce knowledge that is not only more objective in some sense - indeed, as she writes, "the goal is better accounts of the world, that is, "science"" (Haraway 1988: 590) - but that also provides a basis on which we can rethink the categories and methods of knowledge production altogether. The utility of such partial, situated perspectives is that they can be at once both disorienting and illuminating, as much of the more artistic, abstract, but also embodied and sometimes whimsical representations inspired by this thinking tends to do as in the geographer Denis Wood's (2011) narrative atlas of the Boylan Heights neighborhood in Raleigh, North Carolina, Laura Kurgan's (2013) early investigations into the accuracy of GPS, Mei-Po Kwan's (2007) work on affective and artistic uses of GIS and in Bergmann and Lally's (2021) recent call for new kinds of software and analysis practices that blend spatial analysis with relational conceptions of space and place. This broader ethos is similarly seen in the work of artists like Lize Mogel (2010), Jenny Odell (2014) and Clement Valla (n.d.), which rather than using the scienticity of the map to make arguments about the existence of inequality, use these reworked maps to question the epistemological position of the map in the first place - to provide alternative, non-Cartesian ways of looking at and conceptualizing the world. ${ }^{1}$

\section{Situated Mapping in Theory and Practice}

Ultimately, positioning Haraway and Wyly as competing theoretical touchstones is a bit tenuous given the meaningful overlaps in their ideas. While each approaches the issue of objectivity from a different angle, together Haraway and Wyly point towards the need to rescue or make use of the purported objectivity of data and mapping, while also remaining skeptical of it. They suggest a vision that is at once attached to the idea of making more 'truthful' knowledge claims by not being seduced by the singular narrative of truth or objectivity embedded in official sources of spatial data and spatial analytical algorithms, while also being more concerned with using said techniques to promote social and spatial justice than to make grand claims to the truth

\footnotetext{
${ }^{1}$ It should be mentioned that there are also resonances within this tradition with longstanding indigenous mapping practices like those documented by Lucchesi (2018). Following work by Rundstrom (1995) and Pearce and Louis (2008), indigenous mappings can be seen as more 'process oriented' ways of engaging with space and place differently, in turn producing spatial narratives that deviate from established western conceptions of space and territory.
} 
of the world. While these theorists and the bevy of work that is captured by their theorizations represent quite different versions of doing critical mapping, my argument is that they are not irreconcilable. And it is precisely through trying to bring these two lines of work together that we might develop a more effective and unified praxis of critical mapping that I tentatively call situated mapping.

Put simply, despite the fact that critical mapping practices so often fall into one of the two camps described previously, we do not have to choose between the twin imperatives of destabilizing our understanding of the objectivity of cartographic knowledge and taking advantage of such a pervasive understanding in order to produce more just social and spatial outcomes, as is often done in critical mapping work. It is possible to simultaneously use maps to prove that inequality exists and that space matters, while also demonstrating that the ways we conventionally think about space through maps are not really sufficient to understand what is actually going on in the world. Much as the emergence of critical GIS represented a fusing of the social theoretical critique of GIS with the practice of actually working with data and making maps (cf. Schuurmann 2000), a situated mapping seeks to bridge these critical uses of GIS across more abstract or conceptual domains and the more immediate uses of mapping to remake the legal and policy apparatus in which we operate.

The goal and, of course, challenge, is doing critical mapping in a way that does not just use maps to prove a point, but also uses mapping as a way of producing new ways of thinking about social and spatial inequalities, and indeed about space and society more generally. It is not enough to simply plot some points on a map or shade a choropleth to demonstrate the spatial clustering of some social ill. Our maps need to not only demonstrate the world as it actually is, but provide us the means to think about and act differently in the world.

While we can critique Harvey's assessment of the "masturbatory" nature of much mapping and data work, it is important to recognize that there's nothing about mapping or data that ought to make it distract us from social change. Data can - and must - be mobilized in such a way that it does not simply serve as a way of delaying meaningful action. At the same time, however, there is also nothing about data that inherently makes it lend itself towards positive action. As Annette Kim (2015) has written, "it is not enough to just put a map 'out there"” (216). Instead, the production and representation of data must be focused on "the formation of political subjects [and] the formation of interpretive frames that can mobilize these subjects for action" (Elwood and 
Mitchell 2013). While an emerging trend towards community-based, participatory geographic research seeks to overturn this trend by promoting the explicit engagement of academic researchers with their broader communities and working towards the ends of the community rather than their own academic research alone (Shannon et al 2020), participatory mapping remains a fraught process that is not necessarily more likely to yield emancipatory visions of the world (Radil and Anderson 2019). As a result, this work picks up on Kim's (2015) call for explorations of whether it is possible to make emancipatory maps that are not participatory, and how one would go about doing so.

Ultimately, a situated mapping seeks to avoid the "view from nowhere" and instead present a mapping from somewhere, a mapping that simultaneously emerges from a particular social and spatial context and seeks to make that context visible and legible. While there is no single way to enact or practice such a situated mapping, it is worth demonstrating what such an approach might look like and how it produces the alternative understandings of the world, as I do in the following section.

\section{Mapping the Geographies of Vacant and Abandoned Properties in Louisville, Kentucky}

In the wake of the 2008 foreclosure crisis, cities around the United States have given their attention over to the growth of vacant and abandoned properties within their midst. But beyond becoming an object of government and public attention, vacant properties have simultaneously become objects of datafication, with a multitude of initiatives emerging in recent years meant to better count, track, map - and ostensibly manage - vacant properties. Louisville, Kentucky, has become exemplary in both respects (cf. Shelton et al 2015).

But for all of the focus on using data as a means of better managing vacant properties, the city has little to show for such efforts. Far from reaching Mayor Greg Fischer's 2013 goal to reduce the number of vacant and abandoned properties by $40 \%$ over three years and $67 \%$ over five years, the number of vacant properties in the city has actually continued to grow over time. While there were 6,739 vacant and abandoned properties in the city as of February 2015, June 2019 saw the total number of vacants climb to $7,351 .^{2}$ Each of these properties is represented by a single address,

\footnotetext{
${ }^{2}$ Data collected from on July 1, 2019 from Louisville Metro Government Department of Codes and Regulations http://portal.louisvilleky.gov/codesandregs/property-reports/vacantstructures. Data was last updated on June 14, 2019 , and the publicly available data portal for vacant properties was deprecated beginning in December 2019.
} 
which is then geocoded - or turned into a corresponding pair of latitude and longitude coordinates - and plotted on a map. Of the 7,351 vacant or abandoned properties in Louisville, 4,210 (or 57\%) are located within the city's predominantly poor and black West End, as seen in the clustering in Figure 1a.

Figure 1a \& 1b: Locations of Vacant Properties and Property Owners in Louisville
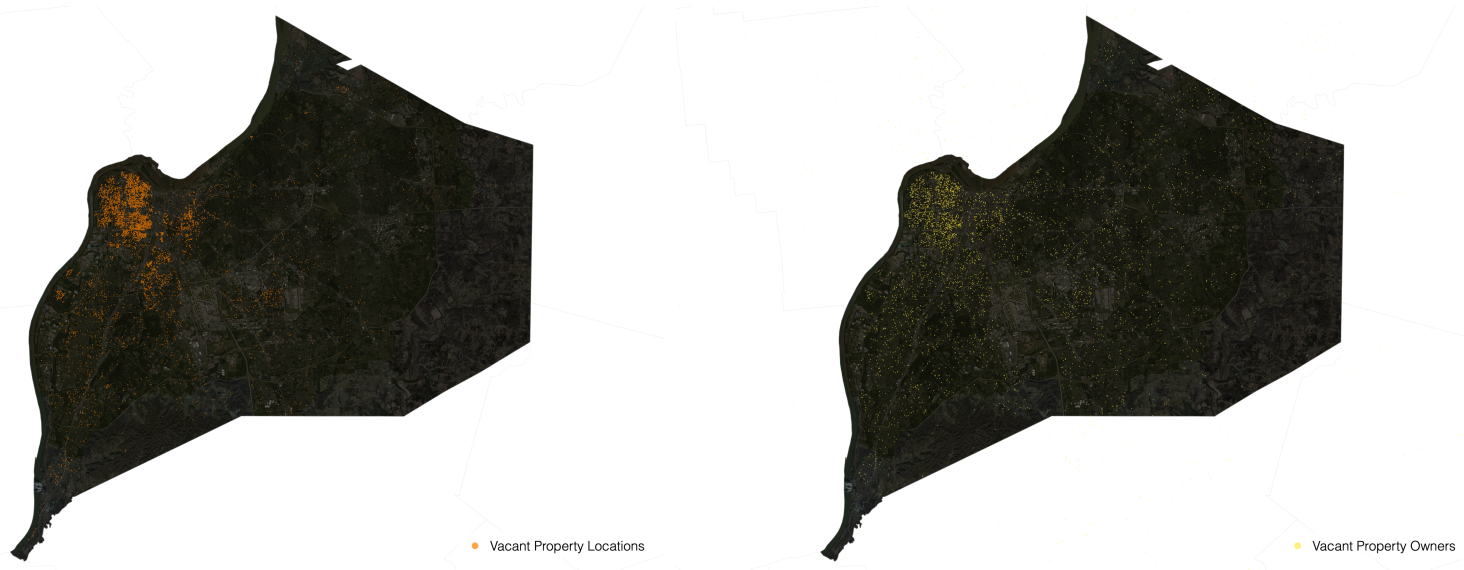

But typical approaches to mapping vacant properties that rely only on this one pair of coordinates can produce problematic impressions of urban social problems, which in turn lead to problematic ways of addressing them. By only visualizing the concentration of these properties in poor and predominantly black neighborhoods, "these kinds of visualizations implicitly blame the people living there for everything from redlining to property speculation and the foreclosure crisis that fed into the production of the city's vacant property problem...despite the fact that many of these problems originate in the desires and actions of more affluent whites living elsewhere in the city (or even outside of it altogether)" (Shelton 2017: 10).

In asking the question "where are Louisville's vacant properties?" we are doing ourselves a disservice if we think of this issue as being simply a 'West End problem'. Following Doreen Massey (2004), it is imperative that we recognize that "any nation, region, city, as well as being internally multiple, is also a product of relations which spread out way beyond it" (6). Indeed, no vacant property is an island. Each one is bound up in processes that stretch far back in time and far beyond the boundaries of the individual parcel. The challenge is how to represent these alternative geographies and use them to inform how we think about the problem of vacant properties and the ways we might go about solving it. 
As such, we are able to introduce a second pair of coordinates from this data into our analysis, which lists the address of each property's owner, and in turn allows us to connect the material manifestations of vacancy in particular places with the people and places responsible for producing these properties as such. As seen in Figure 1b, even mapping the location of vacant property owners across Louisville gives a much different understanding of the issue, and displaces one's focus from exclusively being on the West End, and in turn opening up new ways of exploring what Ananya Roy (2017) calls "the urban land question, specifically who owns land and on what terms, who profits from land and on what terms, and how the ownership, use, and financialization of land is governed and regulated by the state" (A2).

Figure 2: Relational Geographies of Vacant Properties in Louisville

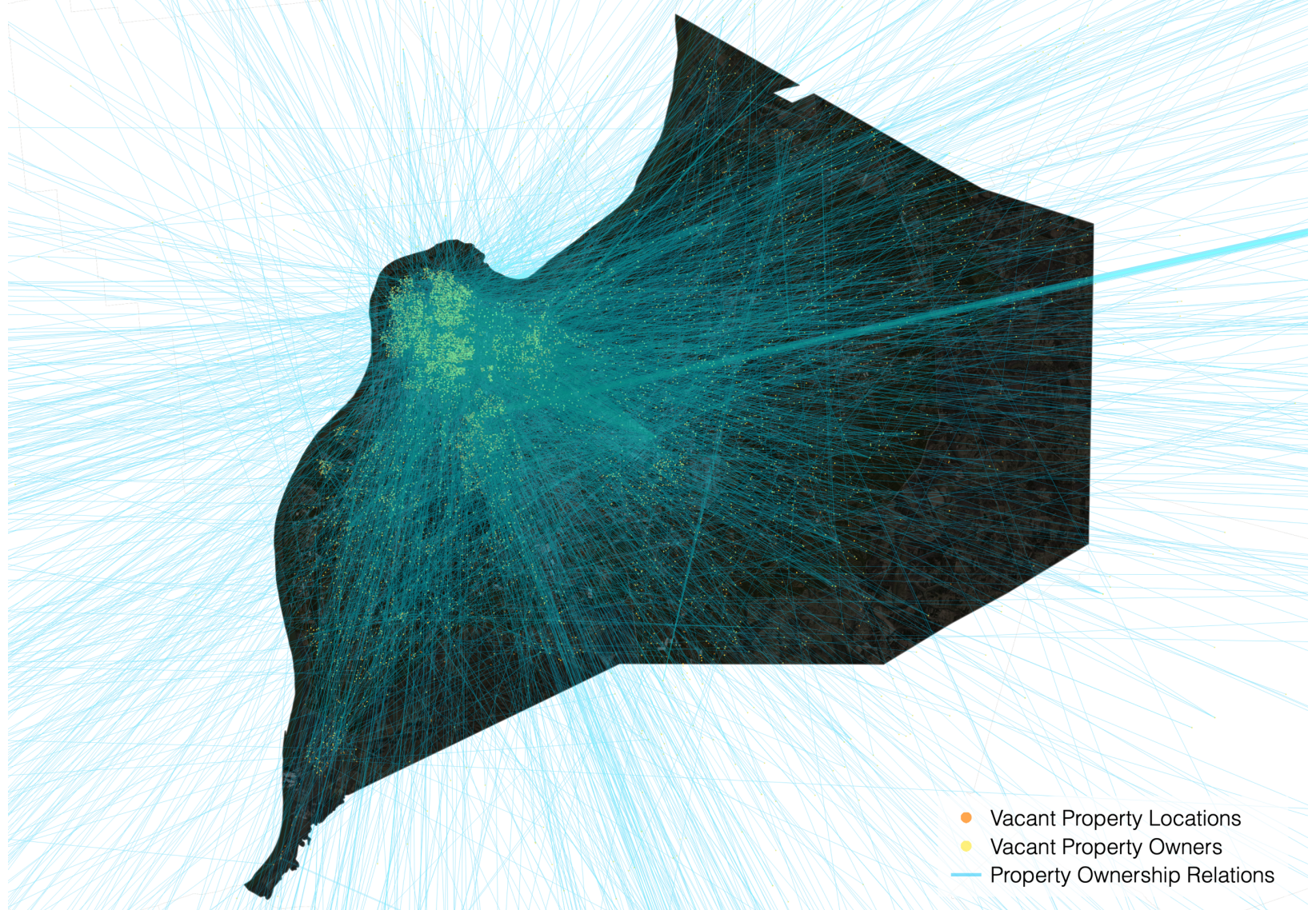

But as with earlier, related work on mapping the relational geographies of property ownership (cf. Shelton 2018), the goal is to show how "the ghetto truly underwrites the suburbs" (Blaut 1974; see also Harris 1972 for a slightly different view of debates over internal colonialism in relation to Black neighborhoods). That is, to show how the seemingly separate sphere of the 
affluent white suburb - a place quite far removed both socially and spatially from the experience of living in proximity to vacant and abandoned properties or other manifestations of housing injustice - is in fact functionally interdependent with such places, as Taylor (2019) demonstrates through her historical account of how the immiseration of black neighborhoods was a precondition for the expansion of white wealth through homeownership and engagement in real estate speculation. So in drawing inspiration from William Bunge's (1971) map of the direction of money transfers in Metropolitan Detroit, Figure 2 maps the relational geographies of vacant and abandoned properties in Louisville, connecting the sites where such vacancy occurs with the often far-flung sites from which vacancy is produced. While quite simple in terms of geometry, even just drawing a straight line from a vacant property to the location of its owner allows for an alternative understanding of the geography of vacancy in Louisville and suggests alternative sites for intervention.

\section{Figure 3: Relational Geographies of Vacant Property Ownership Across the United States}

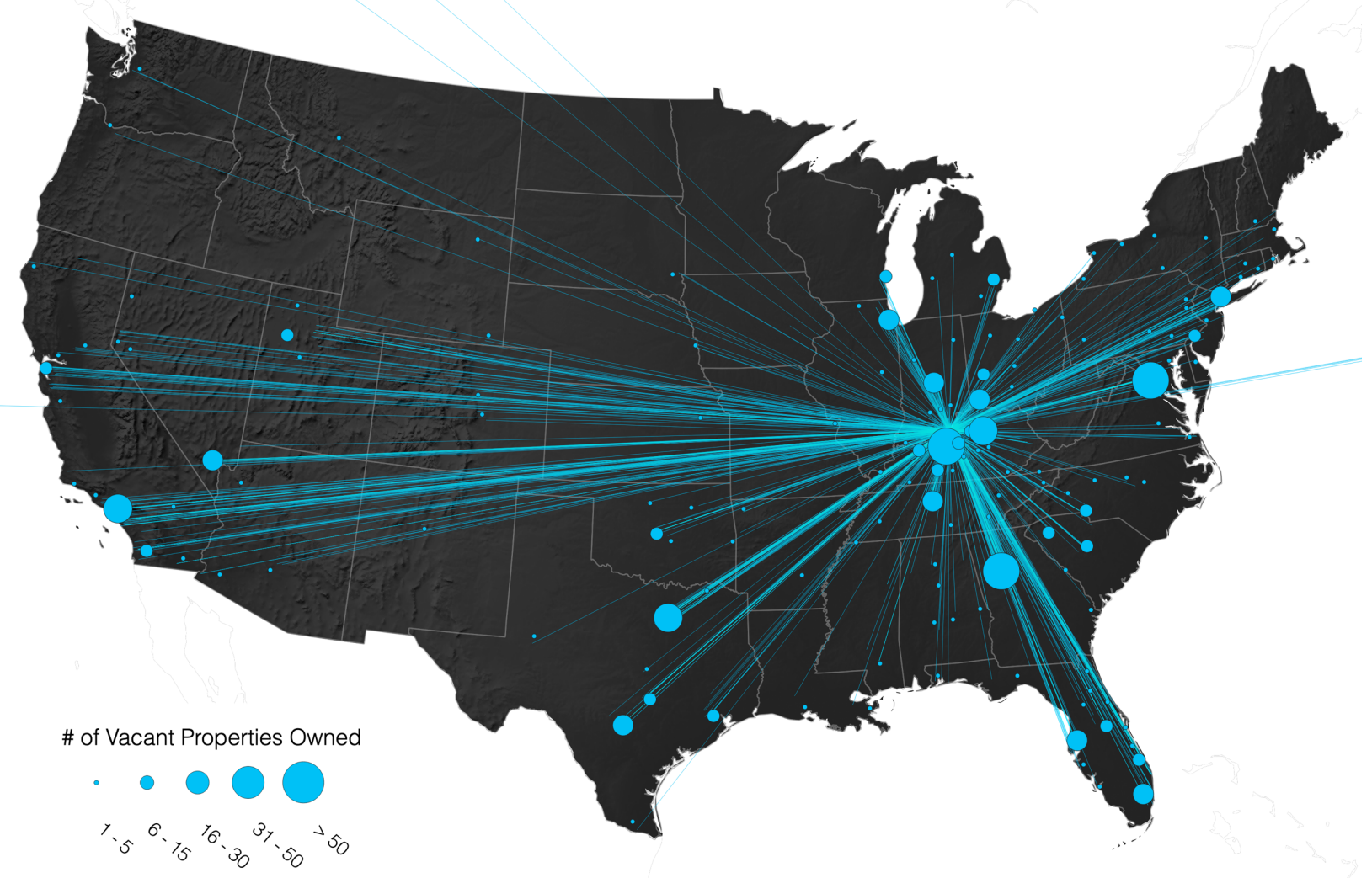


The geography of vacant properties in Louisville is not just about the clustering evident in the West End, but also about the webs of relationships that span the city and beyond, linking the locales where this vacancy 'takes place' and the ownership of these properties from places quite far away. Beyond the significant number of foreclosed properties owned by banks headquartered in major metropolitan areas, a major contributor to the current rash of vacant properties across American cities - and indeed in Louisville - has been the number of absentee real estate investors buying up and speculating on such properties (cf. Monroe 2017).

Notably, while $57 \%$ of Louisville's vacant and abandoned properties are located in the predominantly poor and black West End, just $22 \%$ of the city's vacant properties are owned in the West End. Indeed, a full 1,548 properties (or 21\% of the city's total) are owned outside of Louisville altogether (see Figure 3). Meanwhile, of the 4,210 vacant and abandoned properties located in the West End, $63 \%$ are owned outside of the neighborhood, signaling a lack of control or power over this particular problem on the part of the residents who are so often blamed for the problems that are manifest in the West End. In other words, Louisville's vacant properties are not just in the West End - or even in the city's other historically black neighborhoods like Smoketown, which also have significant concentrations of vacancy. By looking simultaneously at the people and places responsible for producing these vacant properties, we can say that Louisville's vacant properties are just as deeply connected with predominantly affluent and white suburban neighborhoods like St. Matthews and Middletown, not to mention cities like Washington, D.C., Atlanta, Dallas and Los Angeles. In understanding how to address these issues, it is these relations that ought be targeted and scrutinized, rather than subjecting already marginalized, disinvested neighborhoods to new rounds of predatory development, financing and gentrification.

\section{Conclusion: Towards a Situated Mapping}

Ultimately, situated mapping represents a way of synthesizing disparate traditions within the broader field of critical mapping that have been developing over the last two-plus decades. While the particular topic and visualizations presented as examples here have been foundational in developing this concept, they certainly do not represent the only manifestation of this attempt at combining an interest in leveraging the power of the map to make concrete social change and making maps differently than we traditionally have. Though not highlighted in-depth in this paper, it is worth mentioning the work of groups like the Anti-Eviction Mapping Project 
(https://antievictionmap.com/) and Property Praxis (https://www.propertypraxis.org/) as other examples of working in the spirit of situated mapping. Like my own work in Louisville, both the AEMP and Property Praxis use spatial data analysis and visualization to not only prove the realities of urban housing inequalities, but also to reshape the frames through which we see these issues and challenge conventions around what kind of data is appropriate for understanding them in the first place. But shared across these different iterations of situated mapping - even if not explicitly named as such - is an emphasis on shifting our focus from exclusively being on those places where different kinds of social problems are experienced towards looking at the places and people responsible for producing those problems in the first place.

Together, these visualizations and the theories that underlie their production point towards my final argument that, contra Harvey's warnings about moral masturbation, data can have a meaningful role to play here if we treat it not as definitive proof of some externally-produced reality, but rather as a vehicle for reimagining social and spatial processes. Again, it is not enough to make maps that demonstrate that yes, in fact, inequality does exist. We need to visualize why it exists, how it is reproduced and who benefits from it. Our maps and data visualizations need to stimulate alternative imaginations of these issues that can in turn beget alternative ways of intervening in them, targeting the root causes of such inequality rather than just their superficial manifestations alone.

\section{References}

Bergmann, L., \& Lally, N. (2021). For geographical imagination systems. Annals of the American Association of Geographers, 111(1), 26-35.

Blaut, J. M. (1974). The ghetto as an internal neo-colony. Antipode, 6(1), 37-41.

Bunge, W. (1971) [2011]. Fitzgerald: Geography of a Revolution. University of Georgia Press.

Elwood, S., \& Mitchell, K. (2013). Another politics is possible: Neogeographies, visual spatial tactics, and political formation. Cartographica, 48(4), 275-292.

Haraway, D. (1988). Situated knowledges: The science question in feminism and the privilege of partial perspective. Feminist Studies, 14(3), 575-599.

Harris, D. J. (1972). The black ghetto as colony: a theoretical critique and alternative formulation. The Review of Black Political Economy, 2(4), 3-33. 
Harvey, D. (1973) [2010]. Social Justice and the City. University of Georgia Press.

Jasanoff, S., \& Simmet, H. R. (2017). No funeral bells: Public reason in a 'post-truth' age. Social Studies of Science, 47(5), 751-770.

Joyner, A. M., \& Parnell, A. M. (2013). Maximizing the Power of Geographic Information Systems in Racial Justice. Clearinghouse Review: Journal of Poverty Law and Policy, 47, 185194.

Kim, A. M. (2015). Critical cartography 2.0: From "participatory mapping" to authored visualizations of power and people. Landscape and Urban Planning, 142, 215-225.

Kurgan, L. (2013). Close Up at a Distance: Mapping, Technology, and Politics. MIT Press.

Kwan, M. P. (2007). Affecting geospatial technologies: Toward a feminist politics of emotion. The Professional Geographer, 59(1), 22-34.

Lucchesi, A. H. E. (2018). "Indians don't make maps": Indigenous cartographic traditions and innovations. American Indian Culture and Research Journal, 42(3), 11-26.

Massey, D. (2004). Geographies of responsibility. Geografiska Annaler: Series B, Human Geography, 86(1), 5-18.

Mogel, L. (2010). Mappa Mundi. Available from:

http://www.publicgreen.com/projects/mappamundi.html

Monroe, R. (2017). Gone Baby Gone. The New Republic. 19 September. Available from: https://newrepublic.com/article/144528/gone-baby-gone-wake-housing-crisis-new-breed-realestate-investor-destroying-america-cities

Odell, J. (2014). Satellite Landscapes. Available from: http://www.jennyodell.com/satellitelandscapes.html

Olsson, G. (2010). Abysmal: A Critique of Cartographic Reason. University of Chicago Press.

Pearce, M., \& Louis, R. P. (2008). Mapping indigenous depth of place. American Indian Culture and Research Journal, 32(3), 107-126.

Radil, S. M., \& Anderson, M. B. (2019). Rethinking PGIS: Participatory or (post) political GIS?. Progress in Human Geography, 43(2), 195-213.

Roy, A. (2017). Dis/possessive collectivism: Property and personhood at city's end. Geoforum, 80, A1-A11.

Rundstrom, R. A. (1995). GIS, indigenous peoples, and epistemological diversity. Cartography and Geographic Information Systems, 22(1), 45-57. 
Schuurman, N. (2000). Trouble in the heartland: GIS and its critics in the 1990s. Progress in Human Geography, 24(4), 569-590.

Shannon, J., Hankins, K. B., Shelton, T., Bosse, A. J., Scott, D., Block, D., Fischer, H., Eaves, L.E., Jung, J-K., Robinson, J., Solís, P., Pearsall, H., Rees, A., \& Nicolas, A. (2020). Community geography: Toward a disciplinary framework. Progress in Human Geography.

Shelton, T. (2017). The urban geographical imagination in the age of Big Data. Big Data \& Society, 4(1), 1-14.

Shelton, T. (2018). Rethinking the RECAP: mapping the relational geographies of concentrated poverty and affluence in Lexington, Kentucky. Urban Geography, 39(7), 1070-1091.

Shelton, T., Zook, M., \& Wiig, A. (2015). The 'actually existing smart city'. Cambridge Journal of Regions, Economy and Society, 8(1), 13-25.

Taylor, K.-Y. (2019). Race for Profit: How Banks and the Real Estate Industry Undermined Black Homeownership. UNC Press.

Valla, C. (n.d.). Postcards from Google Earth. Available from: http://www.postcards-fromgoogle-earth.com/

Wood, D. (2011). Everything Sings: Maps for a Narrative Atlas. Siglio Press.

Wyly, E. (2009). Strategic positivism. The Professional Geographer, 61(3), 310-322. 